\title{
Oesophageal motor events at the occurrence of acid reflux and during endogenous acid exposure in healthy subjects and in patients with oesophagitis
}

\author{
F BALDI, F FERRARINI, R BALESTRA, D BORIONI, \\ ANNAMARIA LONGANESI, M MIGLIOLI, AND L BARBARA \\ From the 3rd Medical Clinic, University of Bologna, Bologna, Italy
}

SUMMARY In order to assess the oesophageal motor events associated with the occurrence of gastro-oesophageal acid reflux and those during endogenous acid exposure, we studied six healthy subjects and nine patients with symptoms and lesions of reflux oesophagitis. In the case of each subject simultaneous pressure and $\mathrm{pH}$ measurements of the distal oesophagus were taken both in fasting conditions and after a standardised balanced meal. Reflux episodes occurred in the absence of a lower oesophageal sphincter relaxation $(34.3 \%, 17.7 \%)$ or in the presence of a relaxation associated $(34.2 \%, 30.8 \%)$ or unassociated $(31.5 \%, 51.5 \%)$ with a peristaltic sequence, in the controls and patients respectively. No significant differences were found between the two groups. During endogenous acid perfusion the distal oesophagus showed mainly a peristaltic motor activity, but the mean hourly number of peristaltic sequences was significantly lower in the patients than in the controls $(33.5 \pm 27.2$ vs $81.5 \pm 3.2, \mathrm{p}<0.01)$. Our results show that the mechanisms of reflux are similar in controls and in patients, while the peristaltic frequency is reduced in the latter. This motor failure may be responsible for the increased reflux duration observed in patients with oesophagitis.

Gastro-oesophageal acid reflux can be assessed and quantified by means of reliable techniques. ${ }^{12}$ Nevertheless, there is no agreement regarding the mechanisms of reflux; this is particularly true with regard to the role of the lower oesophageal sphincter. Some authors ${ }^{3-5}$ consider a low basal tone of the lower oesophageal sphincter a major cause of reflux, whereas others ${ }^{67}$ suggest that reflux may be related to sphincteric relaxations, particularly when they occur in the absence of a peristaltic sequence.

Moreover, manometric studies have shown a failure of the peristaltic function of the oesophageal body in patients with oesophagitis both in basal conditions $^{8-11}$ and during exogenous acid exposure of the oesophageal mucosa. ${ }^{12}{ }^{3}$ Little information is available regarding oesophageal motility during reflux induced endogenous acid exposure.

The aim of our study was to evaluate, in normal subjects and in patients with oesophagitis: (a) the oesophageal motor events at the occurrence of

Address for correspondence: Dr F Baldi, III Clinica Medica, Policlinico S. Orsola, via Massarenti n. 9, 40138 Bologna, Italy.

Received for publication 15 June 1984 gastro-oesophageal acid reflux, and (b) the motor activity of the distal oesophagus during acid reflux.

\section{Methods}

SUBJECTS

We performed oesophageal motility and $\mathrm{pH}$ studies on six healthy volunteers (four men, age range 23-41 years) and nine patients (six men, age range 24-59 years) with heartburn and/or regurgitation of at least six months duration and endoscopically proved erosive oesophagitis, in the absence of peptic stricture.

Informed consent was obtained from each volunteer and patient before commencing the study. Oesophageal manometry was performed with a polyvinyl probe (Dentsleeve, Australia) consisting of eight catheters (id $0.8 \mathrm{~mm}$, od $1.2 \mathrm{~mm}$ ) fused together (od $4.5 \mathrm{~mm}$ ) with distal side holes. Lower oesophageal sphincter pressure was monitored with a sleeve sensor $6 \mathrm{~cm}$ in length and $5 \mathrm{~mm}$ in width.

For gastric and oesophageal body motility we used the catheters whose side holes were $1 \mathrm{~cm}$ distal to the distal end of the sleeve and 5 and $10 \mathrm{~cm}$ 
proximal to its proximal end, respectively. Each catheter was continuously perfused with bubble free water $(0.5 \mathrm{ml} / \mathrm{min})$ by means of a pneumohydraulic system (Beckman, mod. 999449); the pressure rise rate was always greater than $450 \mathrm{mmHg} / \mathrm{sec}$ on sudden occlusion of the side holes. The recording catheters were connected to pressure transducers (Statham P23 ID, Puerto Rico) fastened to a metal arm. The transducers were always kept at the same level as the corresponding recording orifice by rotating the metal arm according to the subject's body position (see below).

The oesophageal $\mathrm{pH}$ was measured with a miniature combined $\mathrm{pH}$ glass electrode (Ingold 440 M4, Switzerland) connected to a $\mathrm{pH}$-meter (Orion 211, USA). An in vitro calibration of the electrode was carried out with two buffer solutions ( $\mathrm{pH} 4$ and 7) before and after each study. The deglutitions were monitored by means of a belt pneumograph placed around the neck. The pressure and $\mathrm{pH}$ tracings and the deglutitions were recorded on a six channel polygraph (C6s, OTE Biomedica, Italy) running at a paper speed of $1.25 \mathrm{~mm} / \mathrm{sec}$.

\section{EXPERIMENTAL DESIGN}

The subjects were studied in the morning after an overnight fast. No medication was allowed for 48 hours before the experiments; smoking was not allowed from the evening before up to the end of the experiments. The manometric assembly was passed through a nostril into the stomach, the lower oesophageal sphincter was located by a continuous pull through and the sleeve sensor was positioned across the highest pressure zone which showed relaxation upon swallowing. Then, the $\mathrm{pH}$ electrode was introduced through the other nostril into the stomach and withdrawn until 8-10 $\mathrm{cm}$ above the lower oesophageal sphincter. The manometric assembly and the electrode were securely taped to the subject's nose and their position repeatedly checked throughout each study. The recordings continued for five hours. The subjects changed their position (sitting-supine) at regular intervals (Fig. 1). A standardised balanced meal was given at the end of the 2 nd hour. The meal consisted of a soup with pasta $30 \mathrm{~g}$, homogenised meat $70 \mathrm{~g}$, and ham $45 \mathrm{~g}$, Parmesan cheese $5 \mathrm{~g}$, mashed potatoes $170 \mathrm{~g}$, whipped apple $150 \mathrm{~g}$ to which $35 \mathrm{~g}$ of a mixture of oligosaccharides (385 Kcal/100 g) was added, sunflower seed oil $10 \mathrm{~g}$ and tap water $200 \mathrm{ml}$. The total calorie content was $850 \mathrm{Kcal}$ with $46 \%$ carbohydrates, $36 \%$ fats and $18 \%$ proteins.

\section{ANALYSIS OF THE RECORDINGS}

Lower oesophageal sphincter basal pressure was calculated every minute by subtracting the
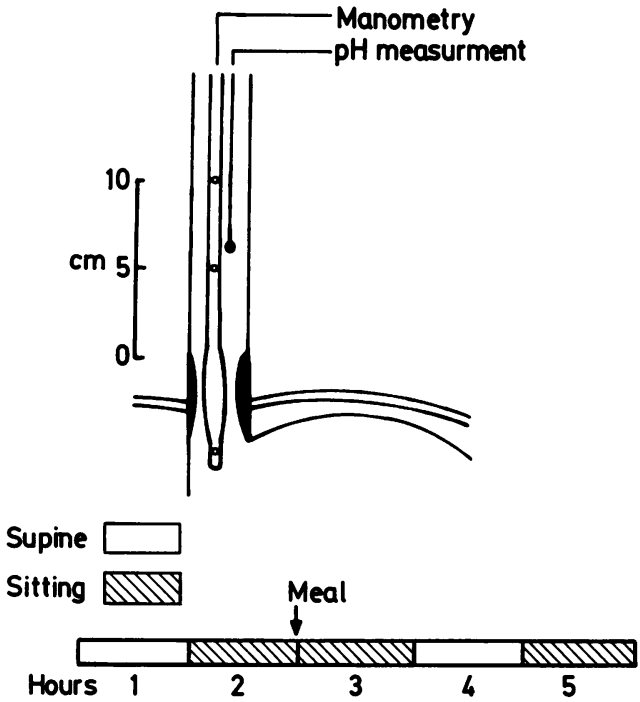

Fig. 1 Methods and experimental design.

corresponding fundic pressure. We did not measure lower oesophageal sphincter basal pressure during and immediately after relaxations of the sphincter and in correspondence with abdominal straining as indicated by an increase of the fundic pressure. The relaxations of the lower oesophageal sphincter were identified by a transient drop of the sphincteric pressure to at least $5 \mathrm{mmHg}$ above the fundic pressure for at least 5 seconds.

Acid gastro-oesophageal reflux was considered to be present when the oesophageal $\mathrm{pH}$ fell below 4 for at least five seconds and was expressed as number of reflux episodes and percentage of time with oesophageal $\mathrm{pH}$ below 4 .

All the motor sequences occurring in the oesophageal body were counted and defined as peristaltic - that is, monophasic non-repetitive waves moving distally between the recording levels in temporal sequence - or synchronous - that is, monophasic waves occurring simultaneously. Their frequency was calculated by extrapolation of the data collected to one hour periods.

The statistical analysis of the results was performed with the Student's $t$ test and the $\chi^{2}$ test, as appropriate.

\section{Results}

The basal pressure of the lower oesophageal sphincter (mean of the five hour study period) was significantly lower in the patients compared with the controls $(8.9 \pm 1.6$ vs $18.3 \pm 3.8 \mathrm{mmHg}$, mean $\pm S D$, 
$\mathrm{p}<0 \cdot 01$, Student's $t$ test for unpaired data). If the mean values for each hour are considered, however, (Fig. 2), the difference between the two groups was significant during the postcibal period only. In both groups the sphincter tone was significantly reduced during the first hour after the meal $(\mathrm{p}<0.01 v s$ the preceding hour, Student's $t$ test for paired data). The control subjects tended to have higher lower oesophageal sphincter pressures in the supine position, whereas this was not clearly seen in the patients. The number of acid gastro-oesophageal acid reflux episodes (mean of the five hour study period) was similar in the two groups (5.8 \pm 2.0 and $7 \cdot 4 \pm 5.1$ in the controls and patients, respectively), while the percentage of time with the oesophageal $\mathrm{pH}$ below 4 was significantly higher in the patient group $(9.6 \pm 7.5$ vs $1.9 \pm 1.0 \%$, mean $\pm \mathrm{SD}, \mathrm{p}<0.01$, Student's $t$ test for unpaired data). Moreover, the reflux pattern was different in the two groups: as shown in Figure 2, reflux episodes were observed in the controls almost exclusively after the meal and predominantly when they were in the upright position, while in the patients reflux was present also in fasting conditions and was not clearly influenced by the body position. The number of reflux episodes was significantly higher in the patients compared with the controls during the 2nd postcibal hour $(2.0 \pm 1.5$ vs $0.5 \pm 0.5$, mean $\pm S D, p<0.05$, Student's $t$ test for unpaired data).

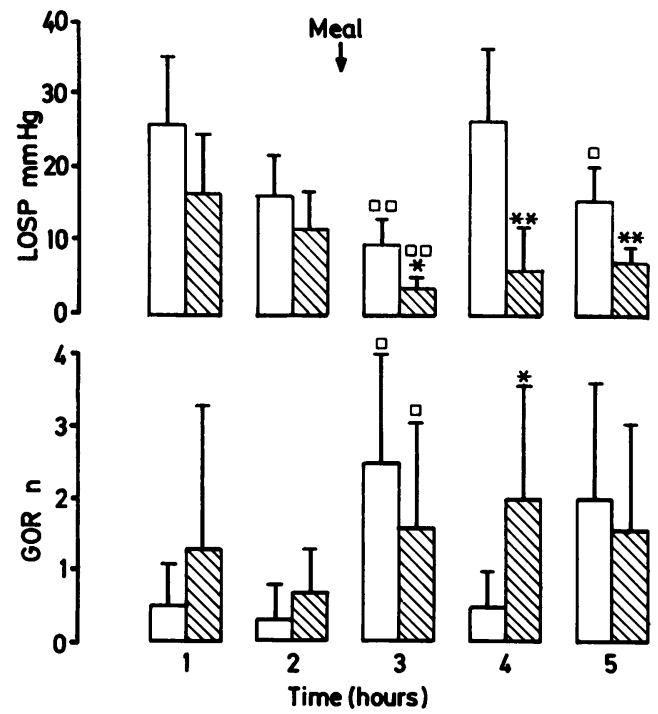

Fig. 2 Pattern of LOS basal pressure (LOSP) and of acid gastro-oesophageal reflux $(G O R)$ in the control $(\square)$ and patient $\mathbb{W}$ groups. The values are expressed as mean $\pm S D$ for each hour. ${ }^{*}=p<0.05 ;{ }^{* *}=p<0.01$ vs controls $\square=p<0.05 ; \square \square=p<0.01$ vs preceding hour.
MOTOR EVENTS ASSOCIATED WITH

GASTRO-OESOPHAGEAL REFLUX

The majority of reflux episodes $(65.7 \%$ in the controls and $82.3 \%$ in the patients, $p$ not significant, $\chi^{2}$ test) were associated with a relaxation of the lower oesophageal sphincter. In order to verify whether this association was related to the basal sphincter tone, we subdivided the reflux episodes into two groups according to the pressure of the lower oesophageal sphincter during the minute preceding the reflux ( $\leqslant$ or $>10 \mathrm{mmHg}$ ). Gastrooesophageal acid reflux invariably occurred through an open sphincter when the pressure was higher than $10 \mathrm{mmHg}$, whereas, when the pressure was lower, this happened in $55.5 \%$ and $78.8 \%$ of the cases in the control and patient group respectively. Relaxations of the lower oesophageal sphincter occurred both in presence of a peristaltic sequence (appropriate) and in its absence (inappropriate) (Fig. 3). The mean number of lower oesophageal sphincter relaxations per hour was significantly lower $(\mathrm{p}<0 \cdot 01$, Student's $t$ test for unpaired data) in the patients than in the controls, both before and after the meal, while the relative frequency of inappropriate relaxations was similar in the two groups (Table 1). In the controls acid reflux was associated with appropriate and inappropriate lower oesophageal sphincter relaxations with similar frequency ( $34.2 \%$ and $31.5 \%$ respectively), whereas in the patients the association with inappropriate relaxations was higher $(30.8 \%$ appropriate and $51.5 \%$ inappropriate) (Fig. 4). The difference between the two groups, however, was not significant. On the other hand, the frequency of inappropriate relaxations associated with reflux was higher in the patients than in the controls $(12.1 \%$ vs $3.9 \%$ respectively, $p$ not significant, $\chi^{2}$ test).

\section{MOTOR EVENTS DURING ACID EXPOSURE}

Table 2 shows the mean hourly number of peristaltic and synchronous contractile sequences in the two groups, subdivided according to the $\mathrm{pH}$ values $(<$ or $\geqslant 4$ ). The peristaltic activity was increased in the control group in the presence of an oesophageal

Table 1 Hourly rate of LOS relaxations (mean $\pm S D$ ) in the control and patient groups

\begin{tabular}{lll}
\hline & Fasting & Fed \\
\hline Controls & $74 \cdot 1 \pm 16 \cdot 7(18 \cdot 1 \%)$ & $45 \cdot 7 \pm 4 \cdot 5(15 \cdot 3 \%)$ \\
Patients & $37 \cdot 8 \pm 9 \cdot 6^{*}(20 \%)$ & $29 \cdot 9 \pm 13 \cdot 7^{*}(17 \cdot 2 \%)$ \\
\hline
\end{tabular}

Figures in parentheses indicate the relative percentage of inappropriate relaxations (see text).

${ }^{*}=\mathrm{p}<0.01$ vs controls. 


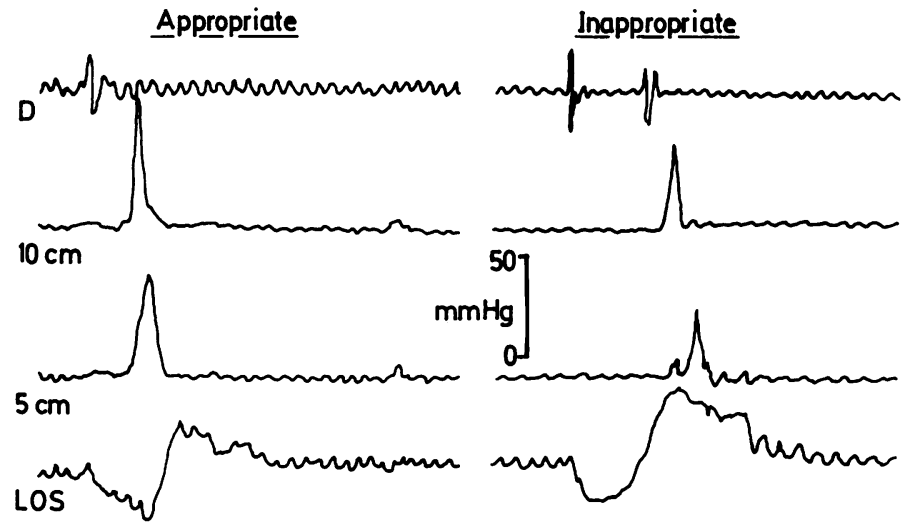

Fig. 3 Patterns of LOS relaxation.
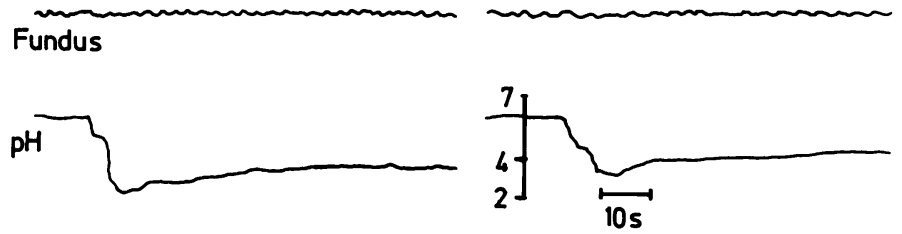

$\mathrm{pH}<4$ (p not significant, Student's $t$ test for paired data). In the patient group the number of peristaltic sequences was significantly lower compared with the controls ( $\mathrm{p}<0 \cdot 01$, Student's $t$ test for unpaired data) regardless of the oesophageal $\mathrm{pH}$, while the synchronous sequences occurred with similar frequency in the two groups.

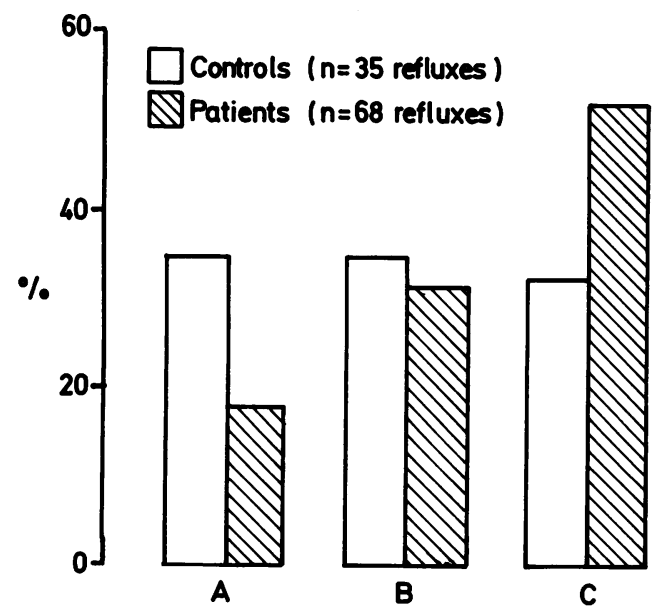

Fig. 4 Frequency of gastro-oesophageal acid reflux occurring in the absence of a LOS relaxation $(A)$ and associated with an appropriate $(B)$ or inappropriate $(C)$ $L O S$ relaxation.

\section{Discussion}

Our results confirm previous findings ${ }^{6} 714$ that the majority of reflux episodes occur in association with relaxation of the lower oesophageal sphincter, both in healthy subjects and in patients with oesophagitis. The frequency of this association seems to be directly related to the basal pressure of the sphincter but, even in the presence of a low lower oesophageal sphincter tone $(<10 \mathrm{mmHg})$, most of the reflux episodes are associated with sphincter relaxations. Therefore the basal tone of the lower oesophageal sphincter, even if low, may prevent the reflux.

It has recently been reported ${ }^{6}$ that some lower oesophageal sphincter relaxations are not preceded by an oesophageal peristaltic sequence (inappropriate relaxations). These have been

Table 2 Hourly number (mean $\pm S D$ ) of peristaltic $(P)$ and synchronous (S) contractile sequences, subdivided according to the oesophageal $\mathrm{pH}$, in the control and patient groups

\begin{tabular}{llllll}
\hline & \multicolumn{2}{l}{$p H>4$} & & & $p H<4$ \\
\cline { 2 - 3 } \cline { 5 - 6 } & $P$ & $S$ & & $P$ & $S$ \\
\hline Controls & $64 \cdot 0 \pm 14 \cdot 1$ & $15 \cdot 5 \pm 2 \cdot 1$ & & $81 \cdot 5 \pm 3 \cdot 2$ & $15 \cdot 5 \pm 4 \cdot 9$ \\
Patients & $29 \cdot 7 \pm 18 \cdot 2^{*}$ & $13 \cdot 3 \pm 13 \cdot 7$ & & $33 \cdot 5 \pm 27 \cdot 2^{*}$ & $16 \cdot 7 \pm 17 \cdot 2$ \\
\hline
\end{tabular}

$*=\mathrm{p}<0.01$ vs controls. 
observed more frequently in patients with oesophagitis than in healthy subjects and $2 / 3$ of them were associated with reflux episodes in the patients. ${ }^{7}$ In our experience inappropriate relaxations account for no more than $20 \%$ of all the sphincter relaxations and their frequency is similar in the patient and control groups (Table 1); moreover, in the patients, only $12 \cdot 1 \%$ of them are associated with reflux. The differences between our results and those of others ${ }^{67}$ might be caused by differing experimental conditions (diurnal with postural changes $v s$ nocturnal in recumbent position). In fact, the mean hourly number of reflux episodes in our patients was similar to that of the controls (Fig. 2), while in Dodds et al's study ${ }^{7}$ the reflux frequency was almost invariably greater in the patients. Certainly the inappropriate lower oesophageal sphincter relaxations contribute to the genesis of reflux, as from $31.5 \%$ to $51.5 \%$ of the refluxes are associated with them, but their role should be considered with caution for two reasons: first, they occur with similar frequency in the patients and controls and, second, only a minority of them are associated with reflux in both groups. Because the majority of the refluxes occur through an open sphincter, whereas lower oesophageal sphincter relaxations are far more frequent than reflux episodes, it is conceivable that for reflux to occur at least one more condition must be present simultaneously, namely an increase in the gastrooesophageal pressure gradient. One might speculate that, in the presence of a mild increase in the fundic pressure, reflux may occur only if the sphincter relaxation is inappropriate, because of the absence of a concomitant oesophageal peristaltic sequence. On the contrary, in the presence of a considerable increase in the fundic pressure, reflux may occur independently of the presence or of the type of lower oesophageal sphincter relaxation. This could explain the greater frequency of the reflux during the postcibal period.

In our study we did not observe significant differences in the mechanisms of reflux between controls and patients nor did they differ as far as the number of reflux episodes was concerned, but, as expected, the duration of reflux was significantly greater in the patient group. The analysis of the motor events during endogenous acid exposure showed that the peristaltic activity of the distal oesophagus was significantly reduced in the patients. This result is in agreement with the impairment of the clearing capacity previously reported ${ }^{15-17}$ in oesophagitis patients. In fact, the peristaltic activity, ${ }^{6}{ }^{16}$ together with the neutralising capacity of saliva, ${ }^{18}$ is considered one of the major determinants of oesophageal acid clearance.
Moreover, whereas our controls showed an increase in the number of peristaltic sequences per hour in the presence of a low oesophageal $\mathrm{pH}$, this was not observed in the patient group. This could be explained by the fact that, as shown by others, ${ }^{13}$ the oesophagus of reflux patients does not have the capacity to lower the threshold of peristalsis in response to intraluminal acid perfusion. The reduction of the peristaltic activity in our patients did not depend on the value of the oesophageal $\mathrm{pH}$, which confirms the previous findings ${ }^{8-11}$ of oesophageal motor abnormalities in patients with reflux oesophagitis.

In conclusion, our data show that (a) the oesophageal motor event most closely related to reflux is lower oesophageal sphincter relaxation, both in the healthy subjects and in patients with oesophagitis and (b) during endogenous acid exposure the distal oesophagus exhibits mainly a peristaltic motor activity, but the peristaltic frequency in the patients with oesophagitis is reduced compared with the healthy subjects. On the basis of our data we cannot tell if this impairment of the oesophageal peristalsis represents a cause or a consequence of reflux. An answer to this question could probably be given by a $\mathrm{pH}$-manometric study undertaken on patients with oesophagitis before and after healing of the oesophageal lesions.

\section{References}

1 De Meester TR, Wang C-I, Wernly JA et al. Technique, indications, and clinical use of 24-hour esophageal pH monitoring. $J$ Thorac Cardiovasc Surg 1980; 79: 656-67.

2 Fisher RS, Malmud LS, Roberts GS, Lobis IF. Gastroesophageal (GE) scintiscanning to detect and quantitate GE reflux. Gastroenterology 1976; 70: 3018.

3 Cohen S, Harris LD. The lower esophageal sphincter. Gastroenterology 1972; 63: 1066-73.

4 Fisher RS, Malmoud LS, Roberts GS, Lobis IF. The lower esophageal sphincter as a barrier to gastroesophageal reflux. Gastroenterology 1977; 72: 19-22.

5 Ahtaridis G, Snape WJ Jr, Cohen S. Lower esophageal sphincter pressure as an index of gastroesophageal acid reflux. Dig Dis Sci 1981; 26: 993-8.

6 Dent J, Dodds WJ, Friedman RH et al. Mechanism of gastroesophageal reflux in recumbent asymptomatic human subjects. J Clin Invest 1980; 65: 256-67.

7 Dodds WJ, Dent J, Hogan WJ et al. Mechanisms of gastroesophageal reflux in patients with reflux esophagitis. $N$ Engl J Med 1982; 307: 1547-52.

8 Olsen AM, Schlegel JF. Motility disturbances caused by esophagitis. J Thorac Cardiovasc Surg 1965; 50: 607-12.

9 Woodward DAK. Response of the gullet to gastric 
reflux in patients with hiatus hernia and oesophagitis. Thorax 1970; 25: 459-64.

10 Ahtaridis G, Snape WJ Jr, Cohen S. Clinical and manometric findings in benign peptic strictures of the esophagus. Dig Dis Sci 1979; 24: 858-61.

11 Baldi F, Ferrarini F, Cassan M, Balestra R, Miglioli M, Barbara L. Manometric evaluation of the oesophageal peristalsis and of the lower oesophageal sphincter in reflux oesophagitis. Ital J Gastroenterol 1982; 14: 145-9.

12 Siegel CI, Hendrix TR. Esophageal motor abnormalities induced by acid perfusion in patients with heartburn. J Clin Invest 1963; 42: 686-95.

13 Corazziari E, Pozzessere C, Materia E, Anzini F. Oesophageal motor response to different intraluminal $\mathrm{pH}$ in reflux patients. Ital J Gastroenterol 1979; 11: 136.
14 Corazziari E, Bontempo I, Anzini F, Torsoli A. Motor activity of the distal oesophagus and gastrooesophageal reflux. Gut 1984; 25: 7-13.

15 Booths DJ, Kemmerer WT, Skinner DB. Acid clearing from the distal esophagus. Arch Surg 1968; 96: 731-4.

16 Stanciu C, Bennett JR. Oesophageal acid clearing: one factor in the production of reflux oesophagitis. Gut 1974; 15: 852-7.

17 Krejs GJ, Seefeld U, Braendli $\mathrm{HH}$ et al. Gastrooesophageal reflux disease: correlation of subjective symptoms with seven objective oesophageal function tests. Acta Hepato-Gastroenterol 1976; 23: 130-40.

18 Helm JF, Dodds WJ, Riedel DR, Teeter BC, Hogan WJ, Arndorfer RC. Determinants of esophageal acid clearance in normal subjects. Gastroenterology 1983; 85: $607-12$. 